\title{
Reality TV e reality show: ficção e realidade na televisão
}

Debora Cristine Rocha

\section{Resumo}

A reality TV, uma variedade da programação factual popular, influencia inúmeros formatos televisivos. Embora o formato mais associado a essa forma de televisão seja o reality show, ela não se restringe a ele e transporta, para a programação em geral, estilos e técnicas que visam tornar seus textos mais e mais reais. Entra em jogo a simulação, um processo de linguagem que faz do mundo vivido - o mundo natural que os signos representam - um sistema de comunicação que alimenta o mundo midiático: o universo criado pela representação. Nesse processo, a comunicação dialoga com a etnografia: dados etnográficos são traduzidos do mundo vivido para o mundo midiático como marcas de veracidade e indicadores de credibilidade. Tanto a reality TV quanto o reality show buscam a etnografia para cumprir a promessa de exibir o máximo de realidade. Porém, no interior de ambos, subsiste a ficção.

Palavras-chave

Reality TV. Reality show. Ficção e realidade. Simulação. Etnografia.

Debora Cristine Rocha I deborarocha111@yahoo.com.br Pontifícia Universidade Católica de São Paulo. Doutora em Comunicação e Semiótica pela Pontifícia Universidade Católica de São Paulo. Membro do Grupo de Pesquisa Espacc - Espaço-Visualidade/ Comunicação-Cultura.

\section{Reality TV}

A televisão vai adentrar a sua casa, vai revirar a sua vida em busca de algo para exibir na telinha. Logo mais, à noite, no horário nobre, a sua história de vida, a sua imagem será transmitida a milhões de pessoas e todo mundo vai saber por um instante, ainda que pequeno, ainda que passageiro, quem você é. Todo mundo vai saber por alguns minutos que você existe, a sua família existe, a sua casa consta no mapa. Todo mundo vai saber que você é real e mais, que a TV é para valer, ela transmite a realidade ao mostrar gente como a gente, o nosso cotidiano. Portanto, a televisão só pode ser digna de crédito, merece a nossa atenção e precisa ser assistida.

Esse é o objetivo que move grande parte da produção televisiva, tornar o sistema de comunicação chamado televisão confiável aos olhos do público para, como mídia doméstica que adentra a moradia de tantos telespectadores diariamente, não ter seus aparelhos desligados ou relegados ao esquecimento. Então, é preciso encontrar lugar na vida privada e rotineira dos telespectadores, é necessário se aproximar do 
público, criar laços, estabelecer uma relação íntima e cotidiana para garantir audiência e realizar-se como sistema de comunicação. Essa é uma exigência própria do sistema, uma necessidade que 0 caracteriza e configura enquanto meio.

Nesse contexto, são inúmeras as estratégias de aproximação criadas pela televisão. Se, em certa etapa de seu desenvolvimento, ela procurou reproduzir mimeticamente 0 cotidiano vivenciado pelo público, agora vai além, quer trazê-lo para dentro da máquina, para 0 interior da programação como marca de veracidade. Trata-se de uma estratégia na qual o referente, o mundo sensível e real, o mundo vivido se torna 0 grande protagonista da TV, ele é o personagem principal e estrutura essa forma de televisão que tem sido denominada como reality $T V$, a TV realidade.

A reality TV é uma variedade da programação factual popular que modeliza os mais diversos formatos televisivos. Embora o formato mais associado à reality TV seja o reality show, ela não se restringe a ele e transporta, para a programação em geral, estilos e técnicas que visam tornar seus textos mais e mais reais. Daí a referencialização da produção televisiva como um todo, pois se busca um efeito de máxima realidade no que é veiculado, o que leva à simulação.

Além dos reality shows, são exemplos de reality TV na televisão brasileira: Domingão do Faustão (TV Globo), Domingo Legal (Sbt) e programas de auditório similares ao exibirem as pegadinhas, pois utilizam a câmera escondida; Linha Direta

(TV Globo), que reconstitui crimes que ocorreram na vida real; Pânico na TV (Rede TV!), ao criar performances que intervêm em acontecimentos reais; Casos de Família (Sbt), talkshow com pessoas anônimas que simula a terapia em grupo;

O Programa da Márcia (TV Bandeirantes) , que utiliza o polígrafo para identificar a traição conjugal; Páginas da Vida (TV Globo), telenovela que insere depoimentos de pessoas comuns ao final de cada capítulo; Lar Doce Lar e Lata Velha, quadros do Caldeirão do Huck (TV Globo), quando o primeiro reforma a casa e o segundo recupera 0 carro de algum telespectador; Retrato Falado, quadro do Fantástico (TV Globo), que reproduz com humor as experiências de mulheres anônimas.

Dada essa diversidade de formatos que a reality TV tem contagiado, há dificuldades para enquadrá-la em determinada categoria:

The category of reality TV is commonly used to describe a range of popular factual programming. There are a variety of styles and techniques associated with reality TV, such as non-professional actors, unscripted dialogue, surveillance footage, hand-held cameras, seeing events unfold as they are happening in front of the camera. However, the treatment of "reality" in reality programming has changed as the genre has developed over the past decade. In the early stages of the genre, reality TV was associated with on-scene footage of law and order, or emergency services. More recently, reality TV is associated with anything and everything, from people to pets, from birth to death. So, how do we categorise this diverse genre? (HILL, 2007, p. 41) 
0 que caracteriza um programa ou quadro televisivo como reality TV não é propriamente o seu formato, mas a utilização de elementos de linguagem que enfatizam o referente $\mathrm{e}$ geram simulações que aproximam a ficção e a realidade. Essa é a essência da reality TV, o destaque dado ao referente, o que o coloca como a menina dos olhos da televisão. Enquanto outros modos de fazer TV admitem limites entre o mundo vivido e o mundo midiático, a reality TV procura eliminá-los.

0 processo que enfatiza o referente e procura reproduzir com total fidelidade os acontecimentos do mundo vivido na TV se configura como simulação. Tal processo se estabelece como um conjunto de estilos e técnicas empregados na produção televisiva, entre os quais se destacam a câmera escondida; a participação crescente de pessoas anônimas na programação; a exibição de celebridades como pessoas comuns; a reconstituição de fatos reais; a exibição do antes-e-depois; a observação do cotidiano de pessoas reais; a intervenção em acontecimentos reais através de performances.

Por um lado, a busca pela simulação se deve a fatores econômicos: "Reality programming provides a cheap alternative to drama" (HILL, 2007, p. 6). De fato, é mais barato produzir programas com anônimos do que celebridades, pois as primeiras se dispõem a aparecer na TV sem remuneração ou, quando muito, em troca de um cachê apenas simbólico diante das cifras astronômicas pagas às estrelas de televisão. Também é mais barato utilizar formatos que não requeiram cenários e figurinos muito dispendiosos, assim como 0 trabalho de profissionais tão disputados e bem remunerados quanto os roteiristas. Além, é claro, da segurança que 0 investimento em programas já testados sempre traz.

Por outro lado, é preciso considerar o interesse do público, afinal, agradá-lo significa audiência. Há, realmente, um voyeurismo midiático, uma vontade de entrever pelos vãos das cortinas, olhar pelas frestas de portas e janelas, observar a vida alheia através do buraco da fechadura a partir dos sistemas de comunicação. É uma fascinação pelo outro que a TV canaliza como isca para prender a atenção do público. Afinal, o voyeurismo midiático é uma prática na qual o indivíduo sente prazer em observar a vida alheia.

No entanto, essa forma de voyeurismo se diferencia da prática voyeur descrita pela psicologia, na qual o prazer, que o indivíduo encontra na observação do outro, é sexual. A utilização televisiva instiga a curiosidade em outro sentido, leva o indivíduo a buscar o que se passa na privacidade de outras pessoas, outras casas, outros estilos de vida. Assim, são coletados hábitos, histórias e comportamentos, diferentes formas de viver.

Tal utilização também indica o quanto a televisão é muito mais do que a telinha que 
emite imagens do cotidiano para um público que as recebe passivamente. Com a reality $T V$, a televisão revela outra face, 0 olho superpoderoso que vasculha o que se passa no espaço da vida privada e transporta o que encontra para 0 espaço da mídia. Então, a TV não opera apenas como emissora da programação, mas ao mesmo tempo como receptora, pois capta a vida diária do público enquanto texto vivido e devolve-lhe o que encontrou como texto midiático.

Ou seja, a TV se propõe a colher textos que fazem parte do mundo vivido, desmontá-los, selecionar partes impregnadas de referencialidade e utilizálas para elaborar outros textos que irão compor a sua programação. Nessa pretensão, ela faz de si mesma um texto que se estrutura pelo processo de montagem, um texto que nada mais é do que a tradução entre 0 texto do mundo vivido e 0 texto do mundo midiático. É uma modelização que, levada a termo pela montagem, desorganiza uma forma de texto, seleciona alguns de seus elementos e reorganiza-os, segundo a linguagem televisiva, numa outra forma textual.

A televisão atua como uma janela indiscreta, cuja vidraça se acomoda na tela de cristal que capta a realidade e reexibe-a em versão midiática. Uma versão que traduz a vida cotidiana como espetáculo e expõe a vida privada de anônimos em público. 0s anônimos representam milhões de telespectadores que, dessa forma, assistirão a si mesmos. Trata-se de uma estratégia que legitima a TV como mídia doméstica.
Na verdade, nada mais adequado. Como mídia doméstica, a TV deve se voltar para o espaço da vida privada do telespectador e esse espaço, comumente preservado do olhar de estranhos, é fundido ao espaço da vida pública para se tornar a vedete da televisão. Surge o espaço privado-público, o carro-chefe da programação.

Mas o que é a exibição desse espaço em rede nacional de TV a não ser a simulação em andamento? E o que é a simulação a não ser 0 diálogo entre a comunicação e a etnografia?

Dados etnográficos são captados por câmeras superpoderosas que devassam a privacidade alheia e são reconfigurados na telinha segundo outra forma de conceber a realidade, a forma dos sistemas de comunicação. Há, portanto, uma semiose entre os dados etnográficos quando utilizados pela etnografia e os mesmos dados quando inseridos num sistema como a televisão. São duas modelizações diferentes que respondem aos olhares da etnografia e da comunicação, duas visões diferenciadas sobre o mundo.

Entrever pelos vãos das cortinas, olhar pelas frestas da janela, observar através do buraco da fechadura são atos associados à dinâmica da simulação. E são todos, sem exceção, atos invasivos, proibidos, que seduzem 0 público pela bisbilhotice. Assim se constrói 0 voyeurismo midiático, que procura manter a atenção do público neste ou naquele texto de cultura, tendo em vista a variedade 
absurda de opções e estímulos para mudar de canal, abandonar um texto e mergulhar em outros. É nesse panorama que um dos traços mais significativos da reality $T V$, a exibição da privacidade, ocupa espaço na mídia.

Há uma mudança profunda na noção de privacidade dos tempos atuais. Formada no século XIX e mantida durante grande parte do século XX, a ideia de privacidade nesse período se apoia num resguardo tão completo da vida doméstica quanto um dogma. Mas, no final do século XX e início do XXI, essa visão é alterada, pois o reconhecimento social passa a ser obtido cada vez mais pela visibilidade. É preciso se fazer ver para ser considerado e, para tanto, não há mais qualquer pudor em expor os detalhes da vida privada, particularidades da vida pessoal. A privacidade deixa a clausura e é colocada à vista de todos. Quanto maior a exposição da vida privada, maior a visibilidade. Quanto maior a visibilidade, maior a inserção social.

E, numa cultura onde os sistemas de comunicação possuem papel preponderante, onde encontrar a maior visibilidade possível se não na mídia? Numa era onde a comunicação modeliza 0 mundo, o maior reconhecimento possível só pode ser encontrado no espaço midiático, o espaço que transforma a vida privada em vida pública através da superexposição, o espaço que dá visibilidade ao anônimo ao exibi-lo como celebridade. Essa é a expectativa de milhões de anônimos que se postam diante dos aparelhos de TV todos os dias, aparecer na televisão e ser reconhecido em meio à multidão que torna 0 indivíduo invisível. 0 exibicionismo midiático é alimentado pela necessidade de reconhecimento.

Mas, para tanto, é preciso devassar a vida privada. E nada melhor do que acompanhar a rotina, o dia-a-dia alheio, pois os atos cotidianos do outro revelam seu mundo pessoal. Não é à toa que a exposição da privacidade explora os modos de viver e fazer de outras casas, outras famílias. No entanto, esses modos de viver e fazer são exatamente o que os etnógrafos buscam observar, pois são estruturas capazes de fornecer dados etnográficos importantes que, nos sistemas de comunicação, serão traduzidos como marcas de veracidade do texto e indicadores de credibilidade da televisão.

Seja como for, é bem verdade que a rotina do outro, tanto quanto o dia-a-dia de quem o observa são repetitivos. Aliás, se existe algo marcado ao extremo pela repetição, só pode ser o cotidiano: acordar, trabalhar, comer, dormir, deslocarse, tomar banho, escovar os dentes. Os atos cotidianos são reproduzidos sistematicamente e trazem consigo o enfado, uma espécie de cansaço e desinteresse dada a falta de novidade. Espiar pode ser sedutor, mas espreitar a insistência, ainda mais na televisão, é enfadonho.

Será que o público quer assistir a um cotidiano tedioso? Espiar pode ser atrativo, mas apenas se for capaz de enfatizar, na vida alheia que se presta à observação, detalhes capazes de 
quebrar a rotina. Esse é um viés muito utilizado na reality $T V$, advindo do jornalismo tabloide ou tabloidismo - que não se restringe aos sistemas impressos, caso dos jornais tabloides tão populares no Reino Unido, mas engloba uma categoria jornalística inteira. Esse modo de fazer jornalismo irá modelizar vários sistemas além dos impressos. Na televisão, ele se apresentará como a tabloid television e alimentará a TV realidade.

0 tabloidismo procurará ressaltar a face escandalosa da vida privada, enfatizar os detalhes escabrosos e chocantes encontrados entre quatro paredes, para tornar a exibição do cotidiano atraente. É uma estratégia para conquistar audiência, na qual a vida privada será apresentada fora do contexto no qual foi captada. Na TV, tal exibição está condicionada à montagem, que seleciona e organiza fragmentos audiovisuais, captados no mundo vivido, em textos do mundo midiático.

A modelização da reality TV pela tabloid television é um dos segredos da sua lógica de funcionamento. Entre essas duas formas de fazer televisão se estabelece um diálogo que pode ser observado em inúmeros formatos televisivos, mas principalmente naquele que identifica a reality TV com maior clareza: o reality show. Afinal, se a reality $T V$ contamina a programação como um todo, é necessário considerar que a maioria dos formatos televisivos já existia antes do seu advento. A exceção será o reality show, que surge com essa variedade da televisão factual popular e alcança tamanho impacto que ambos, reality TV e reality show, chegam a ser confundidos como um único fenômeno.

\section{Reality show}

Ainda que a reality $T V$ modelize a programação como um todo, é preciso considerar que a maioria dos formatos televisivos contagiados por ela já existiam antes do seu advento, o que permitiu a essa variedade televisiva passar quase despercebida. Porém, o surgimento do reality show, um formato criado por esse modo de fazer televisão e totalmente pautado por sua lógica de funcionamento, confere grande visibilidade à reality $T V$. Afinal, 0 impacto do reality show é tão grande que não se restringe à televisão, mas afeta os sistemas de comunicação em geral.

A grande capacidade de dialogar com outros formatos e sistemas de comunicação, modelizando-os com rapidez, é uma característica que tem sido demonstrada tanto pelo reality show quanto pela reality TV. A partir dessa dinâmica, o reality show exibe um leque de opções, em constante expansão, que ultrapassa a dicotomia informação ou entretenimento.

Há reality shows que privilegiam a informação, outros dão mais atenção ao entretenimento, embora o formato sempre exiba uma mistura dessas duas vertentes. Mesmo quando informa, 0 reality deve entreter e, quando entretém, informar. Trata-se do infoentretenimento (HILL, 
2007), no qual programas e quadros televisivos informam e entretêm o público ao mesmo tempo.

É o caso do Caldeirão do Huck (TV Globo), programa de auditório que exibe o Lata Velha, quadro que transforma o carro velho de um telespectador num carrão. 0 Lata Velha não é propriamente um game show, apesar de possuir elementos próprios dessa forma de entretenimento. 0 que dá audiência ao programa é a transformação, o chamado antes-e-depois, ao mostrar como o carro era e como ficou, após um banho de loja nas oficinas parceiras do Caldeirão do Huck. Para o público, a transformação acontece passo a passo, progride cena a cena, enquanto são exibidas imagens que enfatizam a perícia dos profissionais especializados, as técnicas e estratégias empregadas para realizar o sonho do telespectador. É um show de tecnologia que entretém e, simultaneamente, informa o público sobre mecânica de automóveis, restauração, materiais, funilaria, pintura e história automobilística.

0 componente lúdico se desloca para a corrida contra o tempo, pois os profissionais dispõem de apenas alguns dias para deixar um carro velho, uma verdadeira lata velha, impecável. Há o cuidado de restaurar 0 veículo, com peças e acessórios originais e não apenas consertá-lo. Outro traço do entretenimento nesse quadro é 0 mistério, o dono do carro não pode ver o veículo durante 0 processo, ele sequer imagina como 0 carro vai ficar. Daí, o ponto alto do quadro ser a exibição do resultado final: 0 veículo pronto no palco do programa de auditório, o motor roncando diante das câmeras e a emoção do feliz proprietário. É a espetacularização - o confronto entre 0 antes velho, emperrado e quebrado, e o depois incrementado, empolgante e poderoso - que causa surpresa e animação, faz do carro puro espetáculo.

No entanto, entre os reality shows com os mais elevados índices de audiência, estão mesmo os game shows. Desenvolvidos, em grande parte, por empresas especializadas, eles são comercializados como fórmulas para as emissoras do mundo todo. As fórmulas estabelecem as regras e a dinâmica de funcionamento do jogo, preveem premiações e punições, a participação ou não do público. São, portanto, prescrições gerais que identificam e diferenciam o programa de qualquer outro, mas conseguem ser flexíveis o suficiente para permitirem que as emissoras, compradoras dos direitos de exibição, realizem alterações para adaptá-las à cultura em que serão mostradas. Daí, ao chegarem a determinado país, as fórmulas sofrerem pequenas mudanças e gerarem versões diferenciadas.

As fórmulas de game shows são muito variadas, mas sempre associam entretenimento a jogo, 0 que pressupõe a competição como eixo central. No Brasil, há game shows que vão desde $O$ Aprendiz (TV Record), versão brasileira do 
americano The Apprentice, do mesmo criador de Survivor, Mark Burnett, até o Grande Perdedor (Sbt), versão brasileira de The Big Diet; além de fórmulas como Ídolos (Sbt; TV Record) e Astros (Sbt), versões brasileiras do britânico Idols. O Aprendiz simula o mundo dos negócios: sob tensão, jovens profissionais devem cumprir tarefas da vida corporativa, o prêmio final será uma vaga de executivo com salário invejável. Em $O$ Grande Perdedor, pessoas que estejam bem acima do peso precisam perder a maior quantidade de quilos por semana. Já em Ídolos (Sbt; TV Record) e Astros (Sbt), garotos e garotas talentosos competem para se tornar pop star.

Em todos esses programas, a competição ocupa o lugar principal. Algumas vezes está direcionada para a performance organizacional (O Aprendiz), outras, depende do desempenho físico e biológico (O Grande Perdedor) ou do talento (Ídolos; Astros); no entanto, virtudes como a força de vontade e o esforço pessoal, muito valorizadas em provas e jogos esportivos, são sempre evidenciadas.

A estrela maior não apenas dos game shows, mas de todos os reality, dados os índices de audiência e 0 impacto midiático mundial, não foge à regra. o Big Brother, fórmula que no Brasil passou a ser conhecida como Big Brother Brasil, ou simplesmente $B B B$, leva o conceito de jogo às últimas consequências. 0 jogo do Big Brother é a competição por um prêmio milionário, sem dúvida, mas também é a disputa pela fama: os participantes não competem apenas por dinheiro, querem um lugar ao sol nos sistemas de comunicação. É a competição pela visibilidade.

Além disso, o Big Brother é o jogo acirrado entre voyeurismo e exibicionismo midiáticos. De fato, o maior atrativo do programa é exatamente esse, possibilitar ao público observar durante 24 horas por dia a rotina de um grupo confinado num estúdio televisivo, chamado sugestivamente de casa. A ideia é vigiar, bisbilhotar, acompanhar a vida alheia sem trégua. Daí, o apresentador do $B B B$ convidar repetidamente: "Vamos dar uma espiadinha?!"

No Big Brother, a bisbilhotice não é apenas uma forma de invadir a privacidade alheia. Ali, ela se transforma em elemento essencial do jogo. Os participantes e o público competem entre si: o público bisbilhota, o participante se mostra. 0 público é voyeur, enquanto o participante é exibicionista. Assim, as duas faces da mesma moeda, voyeurismo e exibicionismo midiáticos, são articuladas, pois quanto mais o participante for notado de modo positivo pelo público, maiores serão as suas chances de permanecer na disputa. É o jogo pela visibilidade.

O Big Brother também joga com a encenação e a autenticidade. 0 público se transforma em detetive para apontar a falsidade ou descobrir a veracidade das atitudes dos brothers. A questão da autenticidade é central na eliminação do programa, o público valoriza sobremaneira 0 brother cujo comportamento na casa seja 0 
mesmo no mundo de fora. Assim, o telespectador costuma votar na permanência de quem conseguir demonstrar de alguma forma ser autêntico nesse sentido.

Dessa forma, observar o outro, identificar o quanto existe de realidade e ficção no que é exibido, tornar-se voyeur e assistir à performance do exibicionista numa casa, que simula a vida doméstica, são elementos que reforçam a ideia de invasão de privacidade. Na era de hackers e jogos digitais, esse apelo é intenso, invadir é um desafio e o ingrediente que todo jogo bom de verdade precisa ter. Vamos invadir, invadir a vida privada, invadir a vida do outro, ainda que de forma simulada, mas vamos descobrir os segredos que 0 cotidiano guarda e transformar a própria vida em jogo.

É claro que existem outros reality shows que destacam o voyeurismo midiático, como Troca de Família (TV Record), baseado na fórmula Trading Spouses da emissora americana Fox. Durante uma semana, duas mulheres, mães de família, com estilos de vida bem diferentes, irão trocar de lugar e viver a vida uma da outra. Nesse período, uma substituirá a outra junto à família e morará na casa dela, com o marido e os filhos dela, viverá a rotina e o cotidiano de outra mulher com hábitos, atitudes e crenças diversos dos seus. Ao mesmo tempo, junto à sua família, na sua casa, com seu marido e seus filhos, estará uma completa estranha desempenhando as suas funções.
Em um dos episódios da segunda temporada (2008), Zaynab, mãe de uma família árabe de São Paulo, troca de lugar com Thereza, mãe de uma família liberal de Recife. Zaynab usa véu e é submissa ao marido, que segue fielmente os preceitos do Islã, enquanto Thereza não suporta ser mandada. Na mesma temporada, Carol, de uma família japonesa de São Paulo, troca de lugar com Zilma, uma mãe de origem alemã que vive numa barraca de camping, numa colônia nudista de Balneário Camboriú. Mas, contrariando o estereótipo, a japonesa Carol se revela extrovertida - ela e suas filhas desfilam numa escola de samba, enquanto Zilma, a mãe naturista, é muito tímida.

\section{Porém, Troca de Família não é um game show} como o Big Brother. Há voyeurismo midiático, sim, mas 0 entretenimento não está na observação contínua de jogadores que competem por um prêmio milionário. 0 game aqui é outro, está focado nas reações das mães que trocam de lugar e das respectivas famílias que recebem as substitutas, pois será preciso que compartilhem suas vidas com pessoas bem diferentes de si mesmas. As mães vão adentrar o espaço da vida privada de outra pessoa, enquanto as famílias terão de receber as substitutas nesse espaço tão pessoal que é a própria casa.

Na escolha dos participantes, a ideia é minimizar as semelhanças entre as mães selecionadas, pois quanto maiores forem as diferenças de estilos de vida, maiores as dificuldades de adaptação e as 
possibilidades de que surjam surpresas, disputas e brincadeiras; aflorem as diferenças entre a família e a substituta; seja despertada a saudade de quem foi substituída. Tudo isso será utilizado na montagem final do episódio e pode ser a maior informação que o público irá encontrar: como lidar com as diferenças.

Através dessa troca de lugares, o público tem a oportunidade de observar a rotina diária de outras famílias e comparar diferenças e semelhanças com a sua própria experiência familiar. Trata-se de uma fórmula que utiliza recursos da linguagem etnográfica, na qual o pesquisador observa atentamente as reações do nativo em seu contexto de origem e fora dele, além de relacionar a cultura estudada com a própria.

Nesse reality, a mãe de família, que troca de lugar com outra mulher na mesma condição, desempenha o papel de estudiosa, pois deve observar com cuidado a rotina diária dessa outra tribo e verificar as necessidades materiais que seus membros possuem. Ao final do programa, ela vai apontar por escrito como 0 prêmio em dinheiro, que cada família recebe pela participação, será gasto. Ou seja, a partir do momento em que a nova mãe se integra àquela família, ela deve procurar compreender a melhor forma de distribuir o prêmio, o que pode ou não atender às expectativas dos anfitriões. Alguns precisam consertar o carro, outros querem viajar e cabe àquela que chega identificar essas necessidades, pois a família que a recebe em geral não fala abertamente sobre isso.

Outro reality show no qual o voyeurismo midiático ocupa posição de destaque é Supernanny (Sbt), a versão brasileira do programa de mesmo nome criado no Reino Unido e exportado para países como Alemanha, Polônia, Holanda, Israel, China e Estados Unidos. No Brasil, a apresentadora Cris Poli desempenha o papel da supernanny, uma superbabá enviada às casas de pais que têm problemas com os filhos. Ela irá lhes ensinar técnicas para disciplinar as crianças e acabar com 0 choro sem motivo, a alimentação fora de hora, a manha e a má criação.

Enquanto a supernanny ensina os pais no programa, milhares de pais, em casa, pegam carona nas aulinhas e aprendem a educar os filhos com o auxílio da televisão. Porém, ao mesmo tempo, encontram entretenimento, pois o público se diverte ao entrar na casa dos outros e ver como criam seus filhos. Nesse tour, 0 telespectador se depara com a birra infantil e 0 descontrole emocional dos pais, mas também se encanta com o beijo e 0 abraço carinhoso entre pais e filhos.

Já No Limite (TV Globo), versão do programa americano Survivor, inaugura a transmissão de reality shows pela TV Globo. Os participantes do programa são levados para um local exótico e isolado, onde não poderão se comunicar com 0 mundo exterior e passarão por testes de 
resistência física e psicológica, próprios dos treinamentos militares para sobrevivência em lugares inóspitos. Na primeira temporada (2000), No Limite 1, o lugar escolhido foi uma praia no Ceará. As próximas duas temporadas (2001), No

Limite 2 e 3, foram gravadas respectivamente numa fazenda no Mato Grosso e na Ilha de Marajó, no Pará.

A fórmula do programa pretende exibir a luta de pessoas anônimas pela sobrevivência num local hostil. Distantes das facilidades do mundo moderno e sofrendo todo tipo de privações, os participantes são divididos em equipes. Eles devem superar obstáculos e agradar à equipe, pois, a cada prova perdida, o grupo irá expulsar um dos seus componentes, o que significa ter de deixar o reality. 0 ganhador leva um prêmio significativo em dinheiro.

As provas fazem jus ao título do programa, de fato deixam os participantes no limite psicológico e físico desde o início. No programa de estreia da primeira temporada,

Após um dia de confraternização num resort das imediações, os participantes partiram para a aventura, levando apenas uma mochila com algumas mudas de roupa. As duas equipes em disputa, batizadas de "Sol" e "Lua", foram largadas perto da praia em questão, onde receberam a orientação de que teriam de andar quarenta minutos, sob um calor de 35 graus, até atingir 0 ponto onde receberiam víveres $\mathrm{e}$ materiais básicos. Quando lá chegaram, depois de muito subir e descer dunas, ficaram sabendo que os caixotes destinados a eles não estavam na areia, e sim boiando no mar, a uns 30 metros da costa. Tiveram de nadar para buscar os su- primentos. Na hora de abrir os caixotes, outra decepção. Em vez de comida farta, apenas uma caixa com frutas exóticas. No lugar do material mínimo para armar uma barraca, somente um pedaço de lona e badulaques como bules velhos ou machadinhas.

$[.$.

a produção conta com a ajuda de sete fuzileiros navais especializados em sobrevivência na selva, além de um médico de plantão. Por um erro que ninguém soube explicar, quando 0 programa começou a ser gravado os fuzileiros ainda não estavam a postos - só apareceram no final do primeiro dia. Apesar de 0 local ser habitat de cobras venenosas e escorpiões, no início 0 médico de plantão não dispunha de soro antiofídico. Essas falhas só serviram para aumentar 0 stress dos protagonistas de No Limite (MARTHE, 2000).

As privações incluem a alimentação diária:

De três em três dias, cada participante recebe uma ração suficiente para garantir de 250 a 300 calorias diárias - mais ou menos o que recebia um prisioneiro de um campo de concentração nazista. "Eles só vão perder peso", diz a nutricionista Márcia Madeira, encarregada de balancear as esquálidas porções. A certa altura, haverá uma prova em que os vencedores terão de saborear uma refeição asquerosa, que pode ser até carne de cobra . "Não teremos dó de ninguém", avisa Zeca Camargo, apresentador de No Limite (MARTHE, 2000).

É importante lembrar que as provas são elementos próprios da narrativa ficcional, caso dos contos de fadas, nos quais o enredo se organiza segundo uma estrutura morfológica constante (PROPP, 1984): o herói deseja conquistar um objetivo por desejo próprio ou devido às circunstâncias; 0 objetivo contará com a superação de uma prova ou obstáculo 
com alto grau de dificuldade; para tanto, o herói conta com auxiliares, mas também se depara com opositores que dificultam a realização da tarefa; 0 herói cumpre a prova, supera o obstáculo e atinge o objetivo; o herói recebe uma recompensa. $\mathrm{Ou}$ seja, no interior do reality show, o formato que promete o máximo de realidade, subsiste uma estrutura narrativa que recupera a ficção.

No caso de No Limite, a recompensa se mostra como um prêmio significativo em dinheiro, é verdade, mas também como fama e sucesso. Entre os americanos, os protagonistas se tornaram verdadeiras celebridades (MARTHE, 2000). Ou seja, verdadeiros heróis, cuja condição heroica é alcançada pela visibilidade midiática que foram capazes de conquistar. Afinal, a fórmula No Limite-Survivor conta justamente com a necessidade de os participantes, promovidos à condição de heróis, tornarem-se visíveis aos olhos do público. Essa será a maior prova que os heróis terão de enfrentar.

Além disso, o programa será em si mesmo uma prova de resistência de difícil superação que se desdobrará em provas menores a serem vencidas a cada episódio. 0s heróis devem conquistar recursos e aliados para ultrapassar os obstáculos propostos pelo programa a cada etapa para evitar a eliminação. 0s heróis também se depararão com opositores que dificultarão a sua jornada. Ao final, um único herói atingirá o objetivo maior de permanecer no programa até 0 fim. Esse herói remanescente conquistará a grande recompensa: um ótimo prêmio financeiro e a glória de ser visível a milhões de telespectadores.

Na verdade, No Limite-Survivor apresentará ao público todos os ingredientes com os quais 0 Big Brother, campeão de audiência dos reality shows, será construído. Porém, se Survivor se torna sucesso absoluto nos Estados Unidos, o Big Brother se torna sucesso no mundo inteiro. Em outros países, Survivor não obtém índices de audiência tão elevados quanto nos Estados Unidos, mas o Big Brother repete seu desempenho em diferentes lugares do planeta. Mas, se os dois programas possuem tantos elementos em comum, qual será o segredo que faz apenas do Big Brother um hit mundial?

Semelhanças à parte, uma das características de Survivor, que se transformou na alma do negócio brotheriano, é a exibição das dificuldades de relacionamento entre os participantes do reality. Esse é o foco principal do Big Brother. Embora Survivor já disponha desse elemento, não faz dele o seu objetivo maior; a ideia-chave do programa é a luta pela sobrevivência de pessoas anônimas num ambiente hostil. Daí a dureza das provas de resistência física e psicológica. Nessa ideia, Survivor concentra a sua face lúdica, o que responde muito bem na cultura americana, mas não em outras culturas.

Já o Big Brother oferece entretenimento ao fazer do voyeurismo-exibicionismo midiático um jogo em si mesmo. Aliás, é exatamente isso que distingue a fórmula Big Brother de outros 
reality que enfocam o voyeurismo. Enquanto os participantes do programa-brothers, sisters ou apenas big brothers - jogam e apontam quem dentre eles será enviado ao paredão, surgem picuinhas e intrigas, acordos e desacordos, alianças e fofocas.

Tais situações poderiam ser rotineiras no mundo vivido, mas tendem a assumir outra dimensão no mundo midiático. Na TV, serão supervalorizadas pela montagem e repetirão uma estrutura narrativa que, no Brasil, dialoga com a telenovela.

\section{A montagem do Big Brother Brasil retoma} uma estrutura narrativa no reality show que o ficcionaliza. Os brothers são literalmente transformados em personagens, e o público revisita, numa nova roupagem, o herói ou protagonista, o vilão ou antagonista, os amigos do herói, os comparsas do vilão. Os personagens se dividem em grupos e enfrentam-se em busca de uma recompensa, o tesouro das narrativas de aventura que, em $B B B$, assume a forma de prêmio milionário. Os coadjuvantes, os personagens secundários podem não obter a recompensa para si, mas podem colaborar para que o protagonista ou o antagonista, ao qual se unem, conquiste-a.

Por vezes, a batalha entre o Bem e o Mal será reencenada na televisão. 0 Bem será associado à veracidade, enquanto o Mal dirá respeito à encenação, vista como fraude. $\operatorname{Em} B B B$, a batalha entre 0 Bem e 0 Mal será pautada por uma ética da autenticidade: 0 Bem será praticado por aquele que exibir um comportamento na casa semelhante ao que exibiria do lado de fora; enquanto o Mal será praticado por quem fizer o contrário. No centro dessa questão, estão as câmeras, o quanto a sua presença pode alterar 0 comportamento de cada brother.

Distinguir veracidade e encenação, identificar quem é quem no programa passa a ser, portanto, uma função primordial do jogo. 0 público brinca de detetive ao esmiuçar o que possa existir por detrás da conduta de cada participante exibida na TV. Ao mesmo tempo, ele se coloca como o mexeriqueiro que sente prazer em olhar a vida alheia mostrada na telinha. Será desse modo que se estabelecerá um pacto entre o programa e o público: 0 programa exibe a vida alheia e 0 telespectador a vigia, o programa oferece a oportunidade e 0 telespectador se transforma em voyeur. Como tal, ele se rende à bisbilhotice, à necessidade de conhecer a vida do outro, em geral, pessoas tão anônimas quanto qualquer telespectador.

Aliás, faz parte da fórmula Big Brother mostrar a transformação de pessoas comuns em celebridades. É 0 que o diferencia da Casa dos Artistas (Sbt), reality que também confina um grupo numa casa durante um longo período. No entanto, todos os participantes da Casa dos Artistas já são famosos, entre as estrelas estão atores, cantores e músicos bem conhecidos. Nessa casa, as celebridades se transformam em gente comum e aproximam-se do público, enquanto na casa brotheriana os anônimos tendem a abandonar sua condição obscura. 
Essa troca de papéis é uma estrutura narrativa que refaz, em linguagem reality, $O$ príncipe $e$ o mendigo, de Mark Twain (1881): o mendigo se torna príncipe - 0 anônimo vira celebridade no Big Brother -, enquanto o príncipe se torna mendigo - a celebridade agora é pessoa comum na Casa dos Artistas. 0 romance que gerou filmes e peças teatrais no mundo todo, assim como uma telenovela de mesmo título (TV Record, 1972) na televisão brasileira, é modelizado como reality show.

No Big Brother, os participantes entram na casa como pessoas anônimas, mas o mesmo não acontece quando deixam o jogo. Isso vale para todos os participantes e não apenas para 0 vencedor final, pois ainda que determinado brother não ganhe o reality, seu desempenho poderá levá-lo à fama. Por isso, a performance do psiquiatra Marcelo (BBB8, 2008), com direito à confissão sobre homossexualidade, torna-se uma garantia de visibilidade. Após a revelação súbita, Marcelo será pop star durante vários dias não apenas na TV, mas em diversos sistemas de comunicação.

Sendo assim, o Big Brother instiga o desejo de conhecer a vida alheia, apimentado com os sonhos de ganhar na loteria e ser pop star. Diante de tal apelo, como resistir?

Afinal, a televisão vai adentrar a sua casa, vai revirar a sua vida em busca de algo para exibir na telinha. Como reality TV e reality show, ela vai simular o mundo vivido no mundo midiático e, se tudo der certo, a simulação conseguirá persuadilo de que entre ambos não há diferença. Para tanto, a TV vai utilizar as técnicas mais avançadas e as estruturas narrativas mais consagradas, vai unir realidade e ficção como simulação.

\section{Referências}

HILL, Annette. Reality TV: audiences and popular factual television. Londres: Routledge, 2007.

LOTMAN, Yuri L. Universe of the mind: a semiotic theory of culture. Bloomington: Indiana University Press, 1990.

MACHADO, Irene. Escola de semiótica: a experiência de Tártu-Moscou para o estudo da cultura. Cotia: Ateliê, 2003.

MARTHE, Marcelo. Voyeurismo sádico. Veja, São Paulo, ed. 1659, 26 jul. 2000. Disponível em: <http://veja.abril. com.br/260700/p 152.html>. Acesso em: 18 jun. 2008.

PROPP, Vladimir Iakovlevitch. Morfologia do conto maravilhoso. Rio de Janeiro: Forense Universitária, 1984 ROCHA, Debora Cristine. Janela indiscreta, a simulação do mundo vivido no audiovisual. Tese (Doutorado em Comunicação e Semiótica) - Programa de Estudos Pós-Graduados em Comunicação e Semiótica, Pontifícia Universidade Católica de São Paulo, São Paulo, 2009. 


\section{Reality TV and reality show: fiction and reality on television}

\section{Reality $T V$ y reality show: ficción y realidad en la televisión}

\section{Abstract}

Reality TV, a variety of popular factual programming, influences numerous televised formats. Although the format more associated with this type of television is the reality show, it is not restricted to it, its styles and techniques are transferred to TV in general, aiming to make its texts even more realistic. Simulation plays an important role, as a language process which makes the lived world - a natural world represented by signs -, a communication system, that feeds the media world - the universe created by the representation. In this process communication dialogues with ethnography: ethnographic data are translated from the lived world into the media world, as veracity and credibility indicators. Both reality TV and reality shows make use of ethnography to fulfill the promise to exhibit the maximum of reality. However, fiction subsists on the inside of both.

\section{Keywords}

Reality TV. Reality show. Fiction and reality. Simulation. Ethnography.

\section{Resumen}

La tele de realidad (Reality TV), una variedad de la programación actual popular, influencia numerosos formatos televisados. Aunque el formato más asociado a este tipo de televisión sea el reality show, no es restringido a él, ya que sus estilos y técnicas son transportados a la televisión en general, pretendiendo hacer sus textos más y más realistas. La simulación desempeña un papel importante, como un proceso de lenguaje que hace del mundo vivido - un mundo natural que los signos representan - un sistema de comunicación, que alimenta el mundo mediático - el universo creado por la representación. En estos procesos la comunicación hace el dialogo con la etnografía: los datos etnográficos son traducidos del mundo vivido para el mundo mediático, como indicadores de credibilidad y veracidad. Tanto la tele de realidad como el reality show hacen uso de de la etnografía para hacer cumplir la promesa de exponer al máximo la realidad. Sin embargo, en el interior de ambos subsiste la ficción.

\section{Palabras clave}

Reality TV. Reality show. Ficción y realidad. Simulación. Etnografía. 


\section{Expediente}

A revista E-Compós é a publicação científica em formato eletrônico da Associação Nacional dos Programas de Pós-Graduação em Comunicação (Compós). Lançada em 2004, tem como principal finalidade difundir a produção acadêmica de pesquisadores da área de Comunicação, inseridos em instituições do Brasil e do exterior.
E-COMPÓS I www.e-compos.org.br I E-ISSN 1808-2599

Revista da Associação Nacional dos Programas de Pós-Graduação em Comunicação. Brasília, v.12, n.3, set./dez. 2009.

A identificação das edições, a partir de 2008 passa a ser volume anual com três números.

\section{CONSELHO EDITORIAL}

Afonso Albuquerque

Universidade Federal Fluminense, Brasil

Alberto Carlos Augusto Klein

Universidade Estadual de Londrina, Brasi

Alex Fernando Teixeira Primo

Universidade Federal do Rio Grande do Sul, Brasil

Alfredo Vizeu

Universidade Federal de Pernambuco, Brasi

Ana Carolina Damboriarena Escosteguy

Pontifícia Universidade Católica do Rio Grande do Sul, Brasil

Ana Silvia Lopes Davi Médola

Universidade Estadual Paulista, Brasil

André Luiz Martins Lemos

Universidade Federal da Bahia, Brasil

Ângela Freire Prysthon

Universidade Federal de Pernambuco, Brasil

Antônio Fausto Neto

Universidade do Vale do Rio dos Sinos, Brasil

Antonio Carlos Hohlfeldt

Pontifícia Universidade Católica do Rio Grande do Sul, Brasil

Arlindo Ribeiro Machado

Universidade de São Paulo, Brasil

César Geraldo Guimarães

Universidade Federal de Minas Gerais, Brasi

Cristiane Freitas Gutfreind

Pontifícia Universidade Católica do Rio Grande do Sul, Brasil

Denilson Lopes

Universidade Federal do Rio de Janeiro, Brasil

Eduardo Peñuela Cañizal

Universidade Paulista, Brasil

Erick Felinto de Oliveira

Universidade do Estado do Rio de Janeiro, Brasil

Francisco Menezes Martins

Universidade Tuiuti do Paraná, Brasil

Gelson Santana

Universidade Anhembi/Morumbi, Brasil

Goiamérico Felício

Universidade Federal de Goiás, Brasil

Hector Ospina

Universidad de Manizales, Colômbia

Herom Vargas

Universidade Municipal de São Caetano do Sul, Brasil

leda Tucherman

Universidade Federal do Rio de Janeiro, Brasil

Itania Maria Mota Gomes

Universidade Federal da Bahia, Brasil

Janice Caiafa

Universidade Federal do Rio de Janeiro, Brasil

Jeder Silveira Janotti Junior

Universidade Federal da Bahia, Brasil

\section{João Freire Filho}

Universidade Federal do Rio de Janeiro, Brasil

John DH Downing

University of Texas at Austin, Estados Unidos

José Luiz Aidar Prado

Pontifícia Universidade Católica de São Paulo, Brasil

José Luiz Warren Jardim Gomes Braga

Universidade do Vale do Rio dos Sinos, Brasi

Juremir Machado da Silva

Pontifícia Universidade Católica do Rio Grande do Sul, Brasil

Lorraine Leu

University of Bristol, Grã-Bretanha

Luiz Claudio Martino

Universidade de Brasília, Brasil

Maria Immacolata Vassallo de Lopes

Universidade de São Paulo, Brasil

Maria Lucia Santaella

Pontifícia Universidade Católica de São Paulo, Brasil

Mauro Pereira Porto

Tulane University, Estados Unidos

Muniz Sodre de Araujo Cabral

Universidade Federal do Rio de Janeiro, Brasil

Nilda Aparecida Jacks

Universidade Federal do Rio Grande do Sul, Brasil

Paulo Roberto Gibaldi Vaz

Universidade Federal do Rio de Janeiro, Brasil

Renato Cordeiro Gomes

Pontifícia Universidade Católica do Rio de Janeiro, Brasil

Ronaldo George Helal

Universidade do Estado do Rio de Janeiro, Brasil

Rosana de Lima Soares

Universidade de São Paulo, Brasil

Rossana Reguillo

Instituto Tecnológico y de Estudios Superiores do Occidente, México

Rousiley Celi Moreira Maia

Universidade Federal de Minas Gerais, Brasil

Samuel Paiva

Universidade Federal de São Carlos, Brasil

Sebastião Albano

Universidade Federal do Rio Grande do Norte, Brasil

Sebastião Carlos de Morais Squirra

Universidade Metodista de São Paulo, Brasil

Simone Maria Andrade Pereira de Sá

Universidade Federal Fluminense, Brasi

Suzete Venturelli

Universidade de Brasília, Brasil

Valério Cruz Brittos

Universidade do Vale do Rio dos Sinos, Brasil

Veneza Mayora Ronsini

Universidade Federal de Santa Maria, Brasil

Vera Regina Veiga França

Universidade Federal de Minas Gerais, Brasi

\section{COMISSÃO EDITORIAL}

Felipe da Costa Trotta I Universidade Federal de Pernambuco, Brasil Rose Melo Rocha I Escola Superior de Propaganda e Marketing, Brasil

\section{CONSULTORES AD HOC}

Arthur Autran Franco de Sá Neto I Universidade Federal de São Carlos

Carlos Eduardo Franciscato I Universidade Federal de Sergipe

Elisa Reinhardt Piedras I Universidade Federal do Rio Grande do Sul

Elizabeth Bastos Duarte I Universidade Federal de Santa Maria

Marcia Benetti Machado I Universidade Federal do Rio Grande do Sul

Sandra Maria Lúcia Pereira Gonçalves I Universidade Federal do Rio Grande do Sul

Suzana Kilpp I Universidade do Vale do Rio dos Sinos

Tattiana Gonçalves Teixeira I Universidade Federal de Santa Catarina

Vander Casaqui I Escola Superior de Propaganda e Marketing

Vicente Gosciola I Universidade Anhembi Morumb

Walter Teixeira Lima Junior I Fundação Cásper Líbero

REVISÃO DE TEXTO E TRADUÇÃO I Everton Cardoso

EDITORAÇ̃̃ ELETRÔNICA I Raquel Castedo
COMPóS I www.compos.org.br

Associação Nacional dos Programas de Pós-Graduação em Comunicação

Presidente

Itania Maria Mota Gomes

Universidade Federal da Bahia, Brasil

itania@ufba.br

Vice-presidente

Julio Pinto

Pontifícia Universidade Católica de Minas Gerais, Brasil

juliopinto@pucminas.br

Secretária-Geral

Ana Carolina Escosteguy

Pontifícia Universidade Católica do Rio Grande do Sul, Brasil

carolad@pucrs.br 